\title{
Genetic Diversity Analysis for Quantitative Traits in Advanced Breeding Lines of Sesame (Sesamum indicum L.)
}

\author{
Hukumchand and S. G. Parameshwarappa* \\ Department of Genetics and Plant Breeding, College of Agriculture University of Agricultural \\ Sciences, Dharwad - 580 005, Karnataka, India \\ *Corresponding author
}

\section{A B S T R A C T}

\section{Keywords}

Sesame, D2

statistics, genetic divergence, variability

\section{Article Info}

Accepted:

25 November 2019

Available Online:

10 December 2019
To study the genetic divergence in sesame (Sesamum indicum L.), a set of 96 advanced breeding lines obtained from different crosses was evaluated during kharif 2018 in a Randomized Complete Block Design in two replications. With the help of Mahalanobis's $\mathrm{D}^{2}$ statistics, the genotypes were grouped into15 clusters. Cluster I was the largest among all clusters comprising 68 lines, Cluster II (11), Cluster V (4) and Cluster XI (2). Remaining Clusters were solitary. The traits such as seed yield per plant (42.43\%), 1000 seed weight (18.44\%), number of capsules per plant (9.25), height to first capsule (6.82) have contributed maximum to genetic divergence. The highest intra cluster distance was recorded in cluster V (19.02) followed by cluster II (15.53) and cluster XI (14.19). The inter cluster distance was highest between the cluster VII and cluster XI (293.64) followed by cluster IV and cluster XI (288.46), cluster XI and cluster XV (283.22) suggesting wide diversity. The lowest inter cluster distance was observed between cluster VI and cluster XI (11.21). Based on cluster means it can be concluded that line DS-188 is very earliest to mature. The line DS-151 has high mean value for plant height and number of branches per plant. The lines DS-187, DS-192 and DS-158, DS-193 can be used to transfer number of capsules, capsule length and seed yield per plant, respectively. The line DS-191 and DS180 for used for improving thousand seed weight and oil content respectively. By using diversity study we observed that the advanced breeding line DS-158 and DS-151 showing higher $\mathrm{D}^{2}$ values so they are highly diverse can be used in crossing programme to get high heterosis and can obtain good recombinants from them.

\section{Introduction}

The word sesame come from Latin word 'sesamum' and Greek word 'sesamon' which means seed or fruit of sesame plant. Sesame (Sesamum indicum. L), also known as 'ellu' in 'Kannada', 'til' in Hindi and 'nuvvulu' in
Telugu, it is most ancient crop known to mankind. It is an indigenous crop of India after groundnut and brassica oilseeds. Weiss (1883) and several other were having view that it was originated in south western Africa. In Africa most of the cultivated and wild species of sesame occurs. It might have 
introduced through countries like Indonesia and Malesia before Aryan dynasty. Sesamum indicum. $\mathrm{L}$, is one among total 13 genera. It belongs to the family Pedaliaceae and order Tubiflorae. There are 36 species including the cultivated species (Sesamum indicum L.) which has chromosome number $2 n=26$.

Sesame contains 34-63 per cent (Uzun and Cagirgan, 2008) and 20-25\% protein hence it is known as 'queen of oilseed', it has soluble sugars up to $15 \%$, Minerals $7 \%$ such as calcium $(1 \%)$ and phosphorus $(0.7 \%)$, it has vitamins such as niacin, folic acid and rich source of tocopherols. It has anti nutritional factors such as oxalate and phytic acid. It also has 20-25\% carbohydrates. Sesame is rich source of antioxidants such as 'sesamin' and 'sesamol' due to which it has longer shelf life.

Sesame seeds can be eaten raw, roasted or parched. They are used in various foods and in making items such as decorated bread, pastry, sweetmeats and halva. Sesame oil is of high quality mainly used for cooking purpose, it is well balanced with all types of fatty acids such as saturated, monounsaturated and polyunsaturated fatty acids. Low graded oil is also used to make paints, lubricants, illuminant, cosmetics and in insect formulations.

Sesame is cultivated in an area of 10.57 million ha around the world with a production of 6.10 million tonnes and productivity of 470 $\mathrm{kg} / \mathrm{ha}$. Among sesame producing Asian countries, India stands first in sesame production. In India among nine edible oilseeds sesame ranks fifth (Anon., 2017). In India it is cultivated in an area of 16.66 lakh ha with production of 7.47 lakh tonnes and productivity of $448 \mathrm{~kg} / \mathrm{ha}$. It ranks second in area among sesame producing countries after Sudan (21.34 lakh ha). Among different sesame producing states in India, Karnataka stands fifth with an area of 0.35 lakh ha, production of 0.22 lakh tonnes with productivity $629 \mathrm{~kg} / \mathrm{ha}$ (Anon., 2018). In Karnataka among different sesame producing districts, Kalaburgi stands first followed by Koppal, Bagalkot, Chickmagalur, Mysore and Bidar (Anon., 2018), Some of the important cultivated varieties of sesame in Karnataka are DS-1 and DSS-9. In the world, Egypt has got high productivity i.e. $1315 \mathrm{~kg} / \mathrm{h}$. India ranks second in area and third in production among oilseed production, (Anon., 2017). The main reason for lower productivity in India is that this crop is cultivated in low and marginal soils under poor management practices and also use of local varieties besides biotic and abiotic stresses.

The success of any crop improvement programme essentially depends on the nature and magnitude of genetic variability present in the crop. The knowledge of nature and magnitude of genetic variability is of immense value for planning efficient breeding programme to improve the yield potential of the genotypes. Improvement in yield is normally attained through exploitation of the genetically diverse parents in breeding programs.

Genetic divergence among parents is essential since the crossing programme involving genetically diverse parents is likely to produce high heterotic effects and also more variability could be expected in the segregating generations. Genetic diversity between populations/genotypes indicates the differences in gene frequencies. For identifying such diverse parents for crossing, multivariate analysis using Mahalanobis $\mathrm{D}^{2}$ statistic (1936) has been used in several crops.

This is a valuable tool to study genetic divergence at inter varietal and sub-species level in classifying the crop plants. The present study was, thus, carried out to ascertain the nature and magnitude of genetic divergence among ninety six advanced breeding lines of sesame. 


\section{Materials and Methods}

Ninety six advanced breeding lines along with checks (JTS-8, TKG-22, GT-10 and DS-5) were evaluated at Main Agricultural Research Station, University of Agricultural Sciences, Dharwad (Karnataka) during kharif, 2018 in a Randomized Complete Block Design with two replications. Each genotype was sown in a single row of $3 \mathrm{~m}$ length at a distance of 30 $\mathrm{cm}$ between the rows and $15 \mathrm{~cm}$ between the plants within the rows. Five plants in each row were selected at random and the data on ten characters viz., days to 50 per cent flowering, days to maturity, plant height $(\mathrm{cm})$, plant height to first capsule $(\mathrm{cm})$, number of branches per plant, number of capsules per plant, capsule length $(\mathrm{cm}), 1000$ seed weight (g), oil content (\%) and seed yield per plant (g).Multivariate analysis was done as per Mahalanobis's $D^{2}$ statistics (1928) described by Rao (1952) and the genotypes were grouped into different clusters following Tocher's method. Contribution of each character for genetic divergence was estimated from the number of times each character appeared in first rank.

\section{Results and Discussion}

The analysis of variance revealed significant difference among the genotypes for each character, indicating the existence of variability among the genotypes for the character studied. Success of any plant breeding programme depends on diversity present within the lines. The seed yield of any crop can be improved by choosing genetically diverse parents. In order to choose diverse parents, multivariate analysis though Mahalanobis $\mathrm{D}^{2}$ statistics was used in various crop plants. It is a powerful tool which measures the level of diversity between genotypes. Bhatt, (1970) and Narayanan and Macefield (1976) demonstrated its usefulness and its success. $\mathrm{D}^{2}$ statistic widely used to solve the divergence at subspecies, intervarietal, species level (Siddique and Swaminathan, 1971). In present study, 96 advanced breeding lines of sesame evaluated to know nature and magnitude of genetic diversity by using multivariate analysis. The genetic diversity among lines was tested using Mahalanobis (1936) concept of generalised distance $\left(D^{2}\right)$, taking into consideration ten important quantitative characters.

The diversity study disclosed that $\mathrm{D}^{2}$ value were ranged from 0.000 to 293.64 indicating that there is presence of substantial level of variability in the lines studied (Table. 1).

The 96 advance breeding lines were distributed to 15 clusters in a random manner (Table. 2). Cluster-I has highest number of lines i.e. 68 followed by cluster-II (11), Cluster-V (4) and cluster-XI (2). Remaining clusters (III, IV, VI, VIUI, VIII, IX, X, XII, XIII, XIV, XV) were solitary clusters having one line each.

There was absence of connection between geographical diversity and genetic diversity (Fig. 1 and 2) and these results are in concordance with Parameshwarappa et al., (2010), Hitesh et al., (2010) and Spandana Bandilla et al., (2011). Cluster-I was the biggest with 68 genotypes have been grouped, it is comprised of advanced breeding lines derived from the crosses such as (DSS- $9 \times$ HT2), (DS-5 $\times$ RT-311), (DSS-9 $\times$ IC-204484), (DSS-9 $\times$ RSE-3) and (DS-5 $\times$ Chinatil). Eleven genotypes have been grouped in cluster-II, comprised of advanced breeding lines derived from crosses like (DS-5 $\times$ DS-10), (SVRP1×RT-351), (AT-101× DS-5), (GT-3×RT-351) and (PKVNT-11 $\times$ GT-3), this also comprises zonal check JTS-8. Cluster-V consisting of four advanced breeding lines obtained from crosses such as (DSS-9 $\times$ T-78), (DS-5×PT-1) including two checks like DS-5 (local check) and TKG-22 (national check). 
Table.1 Intra and inter Cluster $D^{2}$ values for fifteen Clusters formed by 96 genotypes in sesame

\begin{tabular}{|c|c|c|c|c|c|c|c|c|c|c|c|c|c|c|c|}
\hline Cluster & I & II & III & IV & $\mathbf{V}$ & VI & VII & VIII & IX & $\mathbf{X}$ & XI & XII & XIII & XIV & XV \\
\hline I & 14.13 & 37.76 & 25.16 & 23.45 & 104.90 & 22.56 & 22.45 & 43.55 & 37.42 & 93.81 & 252.17 & 74.14 & 52.60 & 70.29 & 37.94 \\
\hline II & & 15.53 & 57.37 & 62.19 & 43.89 & 31.83 & 46.85 & 28.73 & 28.46 & 31.48 & 137.10 & 47.89 & 28.63 & 28.70 & 71.84 \\
\hline III & & & 0.00 & 28.48 & 114.03 & 19.40 & 38.87 & 41.56 & 39.52 & 117.38 & 269.60 & 97.69 & 90.70 & 103.49 & 41.00 \\
\hline IV & & & & 0.00 & 140.66 & 43.43 & 33.68 & 65.72 & 73.98 & 134.63 & 288.46 & 89.73 & 85.61 & 123.18 & 32.98 \\
\hline $\mathbf{V}$ & & & & & 19.02 & 89.88 & 134.80 & 44.84 & 77.08 & 38.11 & 56.70 & 117.70 & 58.42 & 35.04 & 140.28 \\
\hline VI & & & & & & 0.00 & 24.78 & 42.98 & 11.21 & 71.61 & 233.74 & 62.12 & 64.07 & 69.24 & 46.47 \\
\hline VII & & & & & & & 0.00 & 56.16 & 27.62 & 91.10 & 293.64 & 42.13 & 73.33 & 85.04 & 48.68 \\
\hline VIII & & & & & & & & 0.00 & 40.35 & 43.97 & 130.54 & 61.07 & 30.35 & 38.21 & 71.95 \\
\hline IX & & & & & & & & & 0.00 & 46.78 & 210.11 & 54.38 & 63.20 & 47.75 & 77.73 \\
\hline $\mathbf{X}$ & & & & & & & & & & 0.00 & 82.43 & 71.72 & 39.18 & 33.99 & 123.43 \\
\hline XI & & & & & & & & & & & 14.19 & 242.84 & 131.00 & 116.61 & 283.22 \\
\hline XII & & & & & & & & & & & & 0.00 & 25.00 & 41.16 & 88.74 \\
\hline XIII & & & & & & & & & & & & & 0.00 & 26.32 & 89.13 \\
\hline XIV & & & & & & & & & & & & & & 0.00 & 127.97 \\
\hline XV & & & & & & & & & & & & & & & 0.00 \\
\hline
\end{tabular}


Table.2 Cluster composition of 96 advanced breeding lines of sesame

\begin{tabular}{|c|c|c|}
\hline Clusters & $\begin{array}{c}\text { Total No. } \\
\text { of } \\
\text { genotypes }\end{array}$ & Genotypes \\
\hline I & 68 & $\begin{array}{l}\text { DS-136, DS-142, DS-103, DS-140, DS-141, DS-114, DS-145, DS-172, DS-105, DS-115, DS-144, DS-150, DS-112, DS-111, } \\
\text { DS-135, DS-143, DS-101, DS-149, DS-102, DS-170, DS-121, DS-153, DS-108, DS-167, DS-164, DS-139, DS-118, DS-175, } \\
\text { DS-133, DS-161, DS-132, DS-137, DS-162, DS-173, DS-166, DS-130, DS-119, DS-138, DS-129, DS-117, DS-125, DS-124, } \\
\text { DS-113, DS-177, DS-171, DS-116, DS-109, DS-134, DS-122, DS-131,DS-157, DS-128, DS-120, DS-168, DS-163, DS-165, DS- } \\
\text { 189, DS-178, DS-186, DS-107, DS-194 (GT-10), DS-190, DS-169, DS-152, DS-185, DS-174, DS-127, DS-154 }\end{array}$ \\
\hline II & 11 & DS-179, DS-184, DS-181, DS-196 (JTS-8), DS-159, DS-182, DS-176, DS-156, DS-106, DS-146, DS-183 \\
\hline III & 1 & DS-126 \\
\hline IV & 1 & DS-123 \\
\hline V & 4 & DS-148, DS-160 (DS-5), DS-195 (TKG-22), DS-155 \\
\hline VI & 1 & DS-110 \\
\hline VII & 1 & DS-151 \\
\hline VIII & 1 & DS-188 \\
\hline IX & 1 & DS-104 \\
\hline $\mathrm{X}$ & 1 & DS-187 \\
\hline $\mathrm{XI}$ & 2 & DS-158 \& DS-193 \\
\hline XII & 1 & DS-191 \\
\hline XIII & 1 & DS-192 \\
\hline XIV & 1 & DS-180 \\
\hline $\mathrm{XV}$ & 1 & DS-147 \\
\hline
\end{tabular}


Int.J.Curr.Microbiol.App.Sci (2019) 8(12): 2970-2979

Table.3 The mean values of ten quantitative characters for fifteen clusters in sesame

\begin{tabular}{|c|c|c|c|c|c|c|c|c|c|c|}
\hline & X1 & $\mathrm{X} 2$ & $\mathbf{X 3}$ & X4 & X5 & X6 & $\mathbf{X 7}$ & X8 & X9 & X10 \\
\hline Cluster 1 & 43.74 & 88.75 & 95.70 & 47.44 & 3.98 & 29.49 & 2.34 & 4.65 & 2.94 & 48.10 \\
\hline Cluster 2 & 43.73 & 88.73 & 104.92 & 43.64 & 4.27 & 50.67 & 2.49 & 9.71 & 3.03 & 48.86 \\
\hline Cluster 3 & 45.00 & 89.70 & 78.33 & 54.27 & 4.50 & 33.13 & 2.23 & 4.37 & 2.59 & 47.75 \\
\hline Cluster 4 & 43.50 & 88.50 & 99.25 & 38.00 & 4.50 & 16.5 & 1.95 & 3.13 & 2.67 & 49.47 \\
\hline Cluster 5 & 44.75 & 89.75 & 108.35 & 59.81 & 4.73 & 48.70 & 2.46 & 13.68 & 2.98 & 47.41 \\
\hline Cluster 6 & 45.50 & 91.00 & 89.83 & 45.50 & 4.25 & 61.75 & 2.57 & 6.94 & 2.78 & 46.34 \\
\hline Cluster 7 & 41.50 & 86.50 & 115.00 & 48.83 & 5.84 & 63.50 & 2.31 & 5.65 & 3.02 & 48.58 \\
\hline Cluster 8 & 39.00 & 84.00 & 96.78 & 65.50 & 5.00 & 39.59 & 2.40 & 9.18 & 2.96 & 50.50 \\
\hline Cluster 9 & 44.50 & 89.50 & 95.00 & 50.84 & 4.34 & 78.83 & 2.34 & 9.16 & 2.99 & 47.53 \\
\hline Cluster 10 & 40.00 & 85.00 & 103.67 & 37.00 & 4.34 & 81.88 & 2.53 & 14.50 & 3.17 & 45.36 \\
\hline Cluster 11 & 40.50 & 85.75 & 111.67 & 50.75 & 4.58 & 52.92 & 2.54 & 19.26 & 2.99 & 47.87 \\
\hline Cluster 12 & 39.50 & 85.00 & 94.17 & 38.67 & 3.84 & 37.04 & 2.65 & 6.76 & 3.62 & 47.40 \\
\hline Cluster 13 & 39.00 & 84.50 & 87.83 & 37.84 & 2.67 & 23.42 & 2.75 & 8.85 & 3.33 & 49.94 \\
\hline Cluster 14 & 44 & 89 & 101 & 55 & 4.67 & 41.4 & 2.5 & 11.16 & 3.45 & 50.62 \\
\hline Cluster 15 & 42.5 & 87.5 & 104 & 44.67 & 4.67 & 34.54 & 2.54 & 4.51 & 2.76 & 38.54 \\
\hline
\end{tabular}


Fig.1 Clustering by Tocher Method

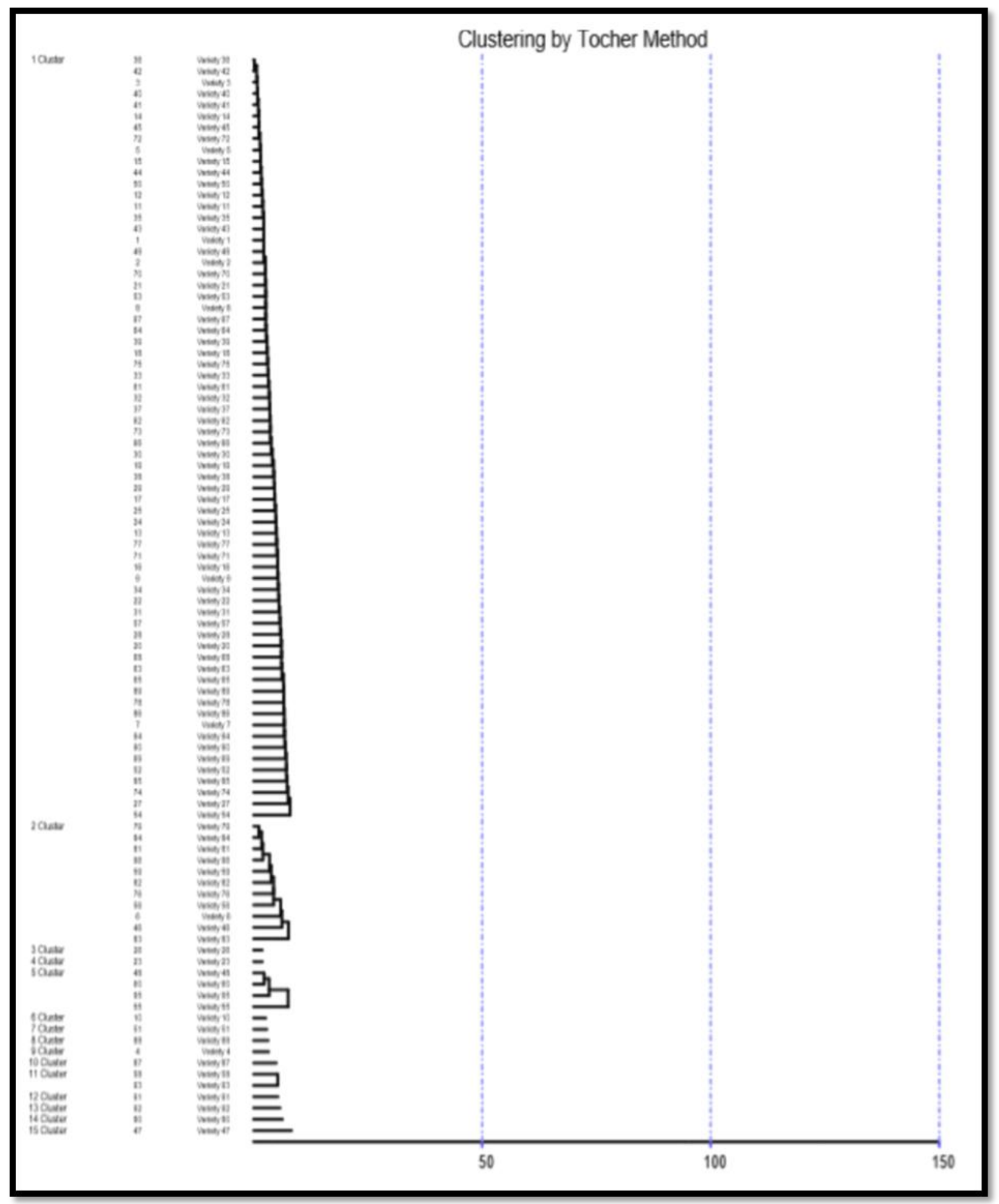


Table.4 Per cent contribution of each character towards divergence

\begin{tabular}{|c|c|c|c|c|}
\hline $\begin{array}{c}\text { Sl. } \\
\text { No. }\end{array}$ & Characters & $\begin{array}{c}\text { Per cent } \\
\text { contribution }\end{array}$ & Ranking & $\begin{array}{c}\text { Times ranked } \\
\text { first }\end{array}$ \\
\hline $\mathbf{1}$ & $\mathbf{X 1}$ & 4.98 & 7 & 227 \\
\hline $\mathbf{2}$ & $\mathbf{X 2}$ & 0.31 & 10 & 14 \\
\hline $\mathbf{3}$ & $\mathbf{X 3}$ & 5.90 & 6 & 269 \\
\hline $\mathbf{4}$ & $\mathbf{X 4}$ & 6.82 & 4 & 311 \\
\hline $\mathbf{5}$ & $\mathbf{X 5}$ & 2.81 & 8 & 128 \\
\hline $\mathbf{6}$ & $\mathbf{X 6}$ & 9.25 & 3 & 422 \\
\hline $\mathbf{7}$ & $\mathbf{X 7}$ & 6.80 & 5 & 310 \\
\hline $\mathbf{8}$ & $\mathbf{X 8}$ & 42.43 & 1 & 1935 \\
\hline $\mathbf{9}$ & $\mathbf{X 9}$ & 18.44 & 2 & 841 \\
\hline $\mathbf{1 0}$ & $\mathbf{X 1 0}$ & 2.26 & 9 & 103 \\
\hline $\begin{array}{l}\text { X1. Days to 50\% flowering } \\
\text { X2. Days to maturity }\end{array}$ \\
$\begin{array}{l}\text { X3. Plant height (cm) } \\
\text { X4. Height to first capsule (cm) } \\
\text { X5. Number of branches per plant }\end{array}$ & $\begin{array}{l}\text { X6. Number of capsules per plant } \\
\text { X7. Capsule length (cm) } \\
\text { X8. Seed yield per plant (g) }\end{array}$ \\
\hline
\end{tabular}

Fig.2 Dendrogram depicting different clusters and their distance

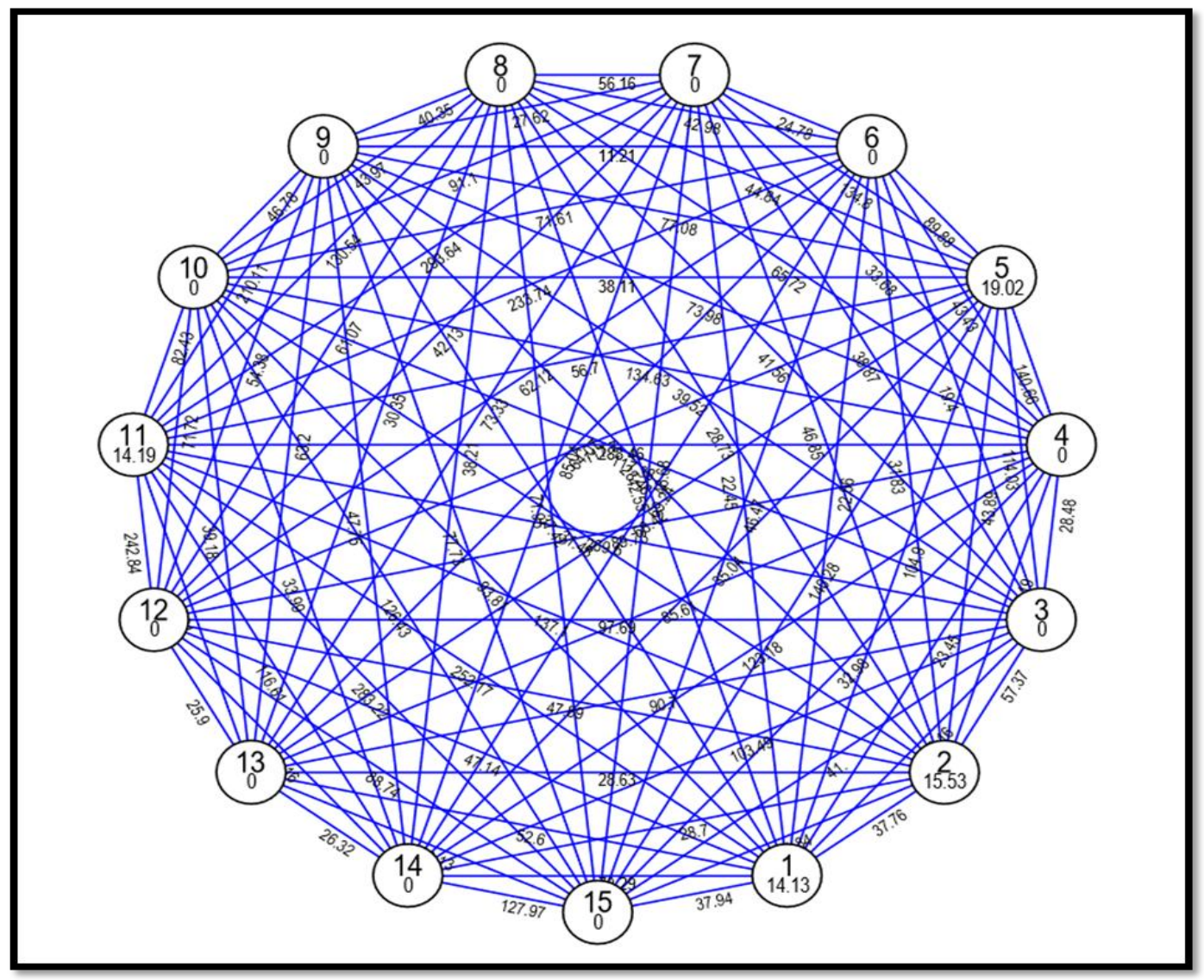


Two genotypes were grouped under cluster-XI comprises of advanced breeding lines obtained from crosses such as (DS-5×PT-1) and it also include check GT-10 (national check). Cluster-VI, VII, VIII, IX, X, XII, XIII, IVX and $\mathrm{XV}$ were solitary clusters comprises of advanced breeding lines obtained from crosses (DS-5×RT-311), (DS-5×Jambakia), (GT-

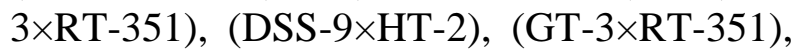
(PKVNT-11×GT-3), (PKVNT-11×GT-3), (GT-3×RT-351) and (DSS-9 $\times$ TKG-377), respectively.

The inter cluster $\mathrm{D}^{2}$ values displaced a very wide range i.e. 11.21 (cluster-IX and VI) to 293.64 (XI and VII) showing presence of substantial level of diversity between the clusters. The intra cluster $\mathrm{D}^{2}$ values ranged from 0.000 (cluster-III, IV, VI, VII, VIII, IX, X, XII, XIII, XIV, XV) to 19.02 (Cluster-V). There was comparative divergence of one cluster from another and higher divergence seen between clusters XI and VII (293.64) followed by clusters XV and XI (283.22), selection of lines to use them as parents for hybridization programme from these clusters will result in unique genotypes and generation of promising crossed material as proposed by Parameshwarappa et al., (2010).There is another way by which superior lines are selected that is based on performance of lines with respect to cluster mean values (Table. 3). Ten quantitative character mean value had considerable differences with respect to all character studied. Cluster-VII had high mean value for plant height and number of branches. Cluster-VIII has high mean value for trait days to maturity and height to first capsule. ClusterVI had high mean value for trait days to $50 \%$ flowering.

Clusters-X, XIII, XI, XII and XIV had high mean value for number of capsules, capsule length, seed yield per plant, 1000 seed weight and for oil content, respectively. While, cluster-IV had low mean value for traits such as number of capsules, capsule length, seed yield per plant and 1000 seed weight. Cluster$\mathrm{X}$ had low mean value for height to first capsule and oil content. Cluster-VIII had low mean value for days to $50 \%$ flowering and days to maturity. Cluster-III and XIII had low mean value for plant height and number of branches per plant respectively. The line in comparable with check has good or better performance will be considered. The cluster with good mean value for traits are used in hybridization and superior genotypes can be produced.

It was observed that the trait seed yield/plant bigger contributor to the divergence followed by 1000 seed weight, capsules per plant, height to first capsule, capsule length, plant height, days to $50 \%$ flowering, number of branches, oil content and days to maturity (Table. 4). The outcomes are in accordance with Sudhakar et al., (2006) and Parameshwarappa et al., (2010). Then six traits viz., seed yield per plant, 1000 seed weight, capsule/plant, height to first capsule, capsule length and plant height were said to be important because together they contributed $89.64 \%$ towards the total divergence and the results are in consonance with Parameshwarappa et al., (2010).

\section{References}

Anonymous, 2017, http//FAO STAT, 2012.

Anonymous, 2018, Directorate of Economics and Statistics, 2017-18.

Bandila, S., Ghanta, A., Natarajan, S. and Subramaniam, S., 2011, Determination of genetic variation in Indian sesame (Sesamum indicum) genotypes for agro- morphological traits. J. Res. Agric. Sci., 7(2): 88-99.

Bhatt, G. M., 1970, Multivariate analysis approach to selection of parents for hybridization aiming at yield improvement in self pollinated crops. 
Australian J. Agric. Res., 21 : 1-7.

Hitesh Kumar, Pritpal Singh and Shashi Banga., 2010, Assessment of phenotypic divergence in a collection of sesame (Sesame indicum L.) germplasm. Crop Improv., 37 (2) : 140-148.

Mahalanobis PC. 1928. A statistical study at Chinese head measurement. Journal of Asiatic Society 25: 301377.

Mahalanobis, P. C., 1936, On the generalized distance in statistics. Proceedings of National Academic Sci., 2: 49-55.

Narayan, R. K. J. and Macefield, A. J., 1976, Adaptive responses and genetic divergence in world germplasm collection of chickpea (Cicer arietinum L.). Theory and Appl. Genet., 47:179187.

Parameshwarappa, S. G., Palakshappa, M. G., Salimath, P. M. and Parameshwarappa,
K. G., 2010, Analysis of genetic divergence in sesame, (Sesamum indicum L.). Karnataka J. Agric. Sci., 23(2): 227-230.

Rao CR. 1952. Advanced Statistical Methods in Biometrical Research.John Wiley and Sons, New York, pp.357369.

Siddique, J. A. and Swaminathan, M. S., 1971, Inter-specific differentiation in Gossypium arboreum. Indian $J$. Genet., 31 : 55-62.

Sudhakar, N., Sridevi, O. and Salimath, P. M., 2006, Genetic divergence in Sesame (Sesamum indicum L.) J. Oilseed Res., $24: 56-58$.

Uzun, B. and Cagirgan, M. I., 2008, Identification of molecular markers linked to determinate growth habit in sesame. Euphytica, 166 (3) : 379-384.

Weiss, E. A., 1983, Oilseed Crops, Longman, London, pp. 280-294.

\section{How to cite this article:}

Hukumchand and Parameshwarappa, S. G. 2019. Genetic Diversity Analysis for Quantitative Traits in Advanced Breeding Lines of Sesame (Sesamum indicum L.). Int.J.Curr.Microbiol.App.Sci. 8(12): 2970-2979. doi: https://doi.org/10.20546/ijcmas.2019.812.345 